\title{
POWER SYSTEM HARMONIC REDUCTION USING SHUNT ACTIVE
}

\section{FILTER}

\author{
Shiuly Mukherjee ${ }^{1}$, Nitin Saxena ${ }^{2}$, A K Sharma ${ }^{3}$ \\ ${ }^{1}$ Jabalpur Engineering College, Jabalpur, Madhya Pradesh, India \\ ${ }^{2}$ Jabalpur Engineering College, Jabalpur, Madhya Pradesh, India \\ ${ }^{3}$ Jabalpur Engineering College, Jabalpur, Madhya Pradesh, India
}

\begin{abstract}
This paper shows the method of improving the power quality using shunt active power filter. The proposed topic comprises of PI controller, filter hysteresis current control loop, dc link capacitor. The switching signal generation for filter is from hysteresis current controller techniques. With the all these element shunt active power filter reduce the total harmonic distortion. This paper represents the simulation and analysis of the using three phase three wire system active filter to compensate harmonics .The proposed shunt active filter model uses balanced non-linear load. This paper successfully lowers the THD within IEEE norms and satisfactorily works to compensate current harmonics. The model is made in MATLAB / SIMULINK and successfully reduces the harmonic in the source current
\end{abstract}

Keywords-Harmonics, shunt active filters, power quality.

\section{INTRODUCTION}

Shunt technology has brought drastic increase in the use of power electronic equipments resulting in the increase of harmonics in source current or ac mains current. intensive use of power converters, various non linear loads and increasing use of office equipments like computers ,faxes ,printers are reasons for the increasing harmonics resulting in deterioration if sources current and source voltage. Harmonics causes very serious damage in powers system. Problems like resonance; overheating of neutral wire, low power factor, damaging microprocessor based equipment. Traditionally, L-C passive filters were used to solve the problem of harmonics to filter out current harmonics to get sinusoidal supply current .Passive filters are classified as single tune filter and high pass filter.

Passive filters have following disadvantages

a) I resonance with the source impedance.

b) fixed compensation, large configuration size.

To overcome the problems of passive filters, active filters were developed and used to solve the problem of harmonics the technology of the active filter has improved a lot thereby giving very good results to reduce the problem of harmonics. The power semiconductor devices improved the active filters a lot. Active filters solve the problem of harmonic in industrial area as well as utilityPower distribution. The active power filter working performance is based on the techniques used for the generation of reference current. With the development various technologies results the lowering of harmonics below $5 \%$ as specifies by IEEE. Efficient ways of generating reference current are $\mathrm{p}-\mathrm{q}$ theory, synchronous reference current theory (SRF method). In this paper SRF method has been used. We have many current control technologies for active power filter, but theHysteresis current controller is proved to be very efficient in terms of fast current controllability and it also very easy to apply when compared to other method like sinusoidal PWM. We can detect harmonics in two ways or two main forms first in time domain and second in the frequency domain the paper deals with Fast Fourier Transform (FFT) is used to find harmonics in frequency domain. Other frequency domain techniques are discrete Fourier transform (DFT); recursive discrete Fourier transform (RDFT).our main target is to reduce THD of supply current with the help of hysteresis band current controller. There are two type of hysteresis Current controller namely, adaptive hysteresis current controller and fixed band current controller. Our paper deals with the use of fixed band hysteresis current controller. The model of shunt active power filter using hysteresis current controller has been used in mat lab/simulink. Results have been successfully retrieved from model and followed by conclusion.

\section{SHUNT ACTIVE POWER FILTER}

The large scale use of power electronics equipment has led to increase in harmonics in the power system. The nonlinear loads generate harmonic current which distorts the voltage waveform at PCC. These current harmonics will result in a power factor reduction, decrease in efficiency, power system voltage fluctuations and communications interference [3]. So harmonics can be considered as a pollutant which pollutes the entire power system. Traditionally a bank of tuned LC filters 
was used as a solution for the problems caused by the system harmonics, since they are easy to design, have simple structure, low cost and high efficiency. [7] Phase advancers synchronous capacitors etc. were also employed for the power system quality enhancement. However traditional controllers have many drawbacks. It provides only fixed compensation, generates resonance problems and are bulky in size [6]. To overcome these disadvantages, active power filters are introduced which compensate for the current harmonics and reduces the total harmonic distortion. The SAPF is connected in parallel with the line through a coupling inductor. Its main power circuit consists of a three phase three-leg current controlled voltage source inverter with a DC link capacitor. An active power filter operates by generating a compensating current with 180 degree phase opposition and injects it back to the line so as to cancel out the current harmonics introduced by the nonlinear load. This will thus suppress the harmonic content present in the line and make the current waveform sinusoidal. So the process comprises of detecting the harmonic component present in the line current, generating the reference current, producing the switching pulses for the power circuit, generating a compensating current and injecting it back to the line. In this paper a nonlinear load supplied by a three phase voltage source is projected. An active power filter is introduced in parallel to this system for the compensation of current harmonics caused by the nonlinear loads. Here SRF algorithm is used for the reference current extraction from the distorted source current, which is being explained in section II. The switching pulses for the power circuit are generated using the Hysteresis Current Control technique as explained in section III and is found to be very effective. The simulation results are projected in section IV. Figure 1 shows a three phase shunt active power filter.

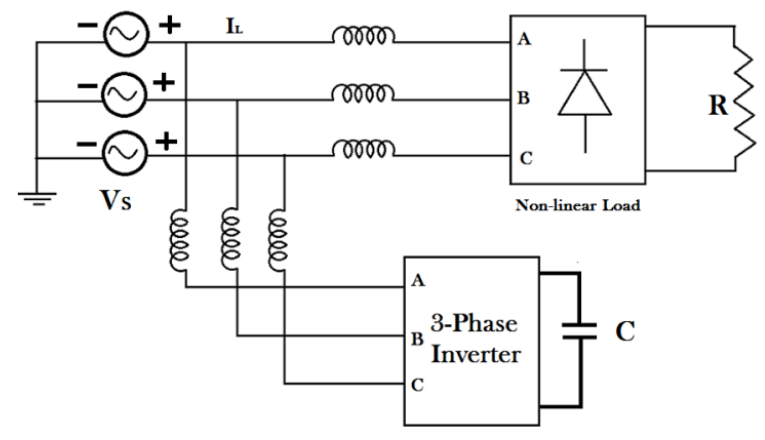

Fig 1 three phase shunt active filter

\subsection{Working Principle of Shunt APF}

The schematic diagram of the single phase load compensator is shown in Figure 25. In this diagram a voltage source is supplying a load that could be nonlinear as well. The point of connection of the load and the source is the point of common coupling (PCC). Since there is no feeder joining the source and the load, we shall designate the source to be stiff. Here the compensator consists of an H-bridge inverter and an interface inductor (Lf). The resistance Rf represents the resistance of the interface inductor due to its finite Q-factor as well as the losses in the inverter. One end of the compensator is connected at the PCC through the interface inductor while the other end is connected with the load ground. The dc side of the compensator is supplied by a dc capacitor Cdc. The inverter is expected to be controlled to maintain a voltage Vdc across the capacitor. Let us assume that the load is nonlinear and draws a load current has a poor power factor. The instantaneous load current then can be decomposed as

$$
i L=i L p+i L q+i L h
$$

Where iLp and iLq are respectively the real and reactive parts of the current required by the load and iLh is the harmonic current drawn by the load. The purpose of the compensator is to inject current ic such that it cancels out the reactive and harmonic parts of the load current.

Now applying KCL at the PCC we get

$$
\mathrm{iL}=\mathrm{is}+\mathrm{ic} \Rightarrow \mathrm{is}=\mathrm{iL}-\mathrm{ic}
$$

We assume that the compensator operates in a hysteresis current control loop in which the compensator current tracks a reference current ic*. Let us now choose this reference current as

$$
i c^{*}=i L q+i L h
$$

If the inverter accurately tracks this reference current, then the source current will be equal to the unity power factor current drawn by the load. Since the compensator does not draw any real current, the average power consumed by the compensator is zero.

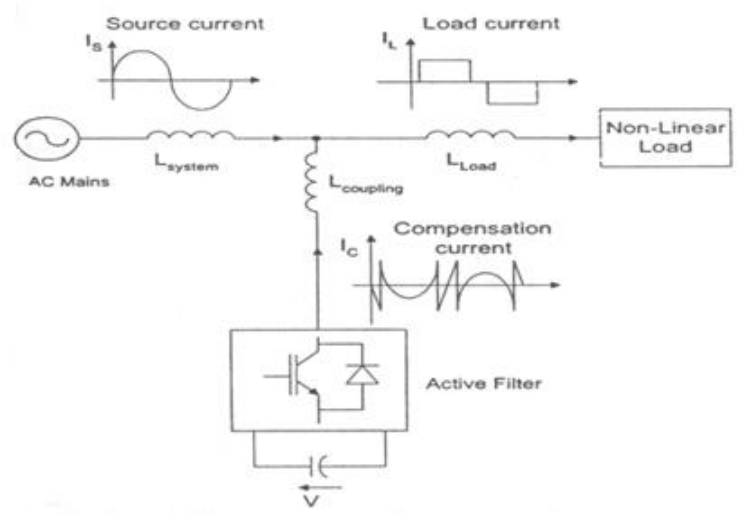

Fig 2: Basic Scheme of shunt active filter

\subsection{Implementation}

The hysteresis band current control (HBCC) technique is used for pulse generation in current controlled VSIs. The control method offers good stability, gives a very fast response, 
provides good accuracy and has got a simple operation [5]. The HBCC technique employed in an active power filter for the control of line current is shown in Figure 3. It consists of a hysteresis band surrounding the generated error current. The current error is obtained by subtracting the actual filter current from the reference current. The reference current used here is obtained by the SRF method as discussed earlier which is represented as Iabc*. The actual filter current is represented asIfabc. The error signal is then fed to the relay with the desired hysteresis band to obtain the switching pulses for the inverter.

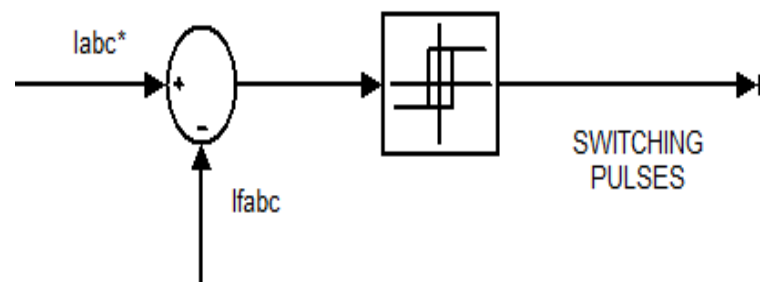

Fig 3: Hysteresis band current controller.

The operation of APF depends on the sequence of pulse generated by the controller. Figure 4 shows the simulation diagram of the hysteresis current controller.A band is set above and below the generated error signal. Whenever this signal crosses the upper band, the output voltage changes so as to decrease the input current and whenever the signal crosses the lower band, the output voltage changes to increase the input current. Accordingly switching signals are generated. [5]

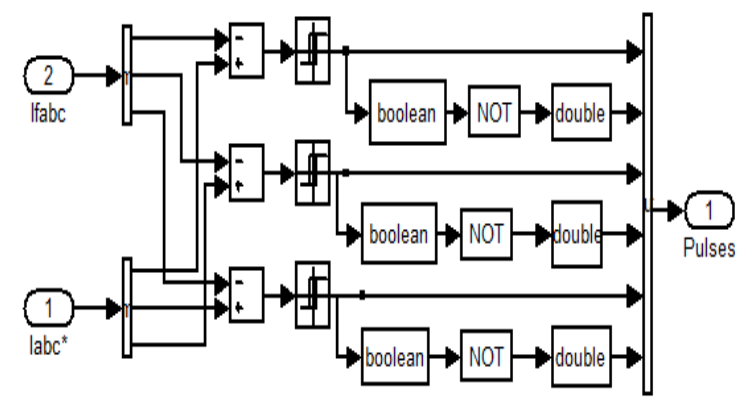

Fig 4: Simulation diagram of hysteresis current control.

The switching signals thus generated are fed to the power circuit which comprises of a three phase three leg VSI with a DC link capacitor across it. Based on these switching signals the inverter generates compensating current in phase opposition to the line current. The compensating current is injected back into the power line at the PCC and thus suppressing the current harmonics present in the line [1]. The overall simulation block diagram is shown in Figure 5.

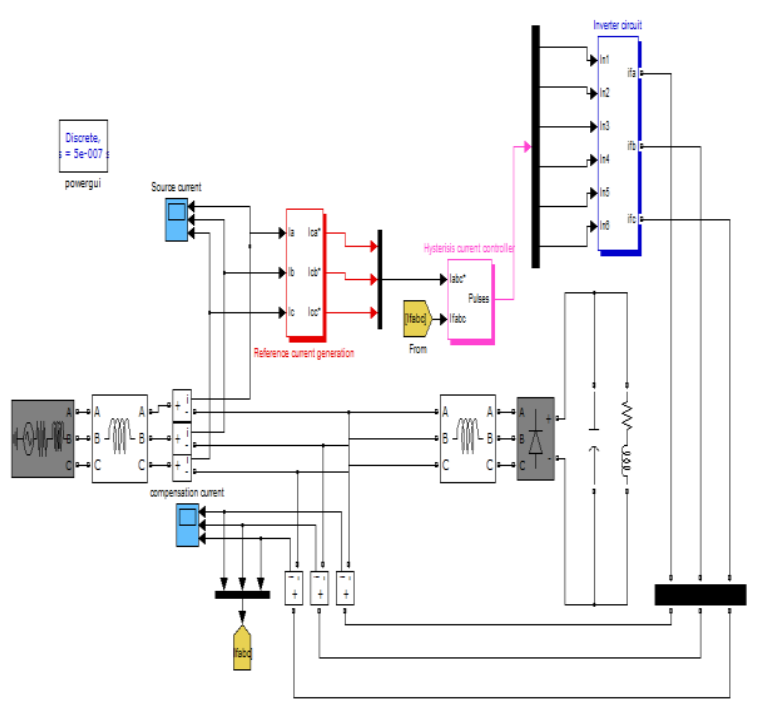

Fig 5: simulation diagram of shunt active filter

\section{SIMULATION RESULTS AND DISCUSSION}

The harmonic current compensation is implemented in a threephase power system using a shunt active power filter. The rms value of source voltage of the system is set as $480 \mathrm{~V}$ and a combination of three-phase universal bridge rectifier with an RLC load across it constitutes the nonlinear load which introduces the harmonics into the system. Table 1 shows the various circuit parameters and design specifications used in this simulation. The source current waveform without filter in a-phase is shown in Figure 6. The Total Harmonic Distortion (THD) spectrum in the system without filter is shown in Figure 7, which indicate a THD of $25.75 \%$. The compensating current waveform in a phase is illustrated in Figure 8. The source current after the injection of compensating current is shown in Figure 9. The THD with active power filter included is observed to be $4.87 \%$ which is within the allowable harmonic limit. Figure 10 shows the THD spectrum with active power filter in the circuit.

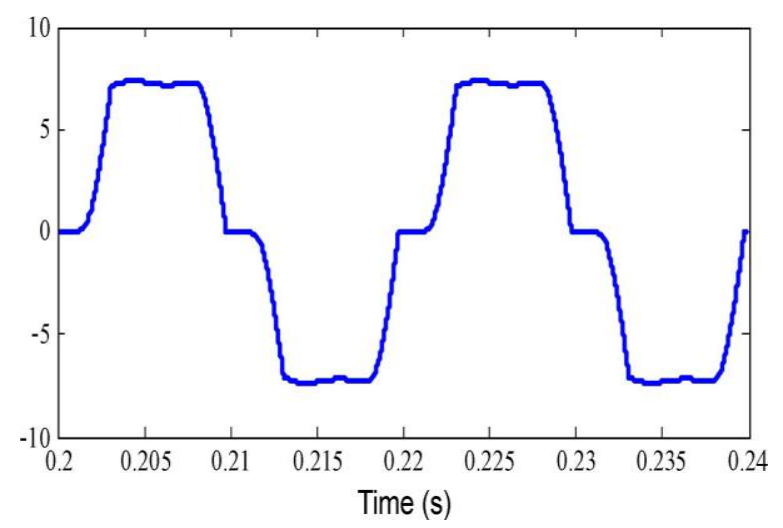

Fig 6 Load current of the phase "a" 


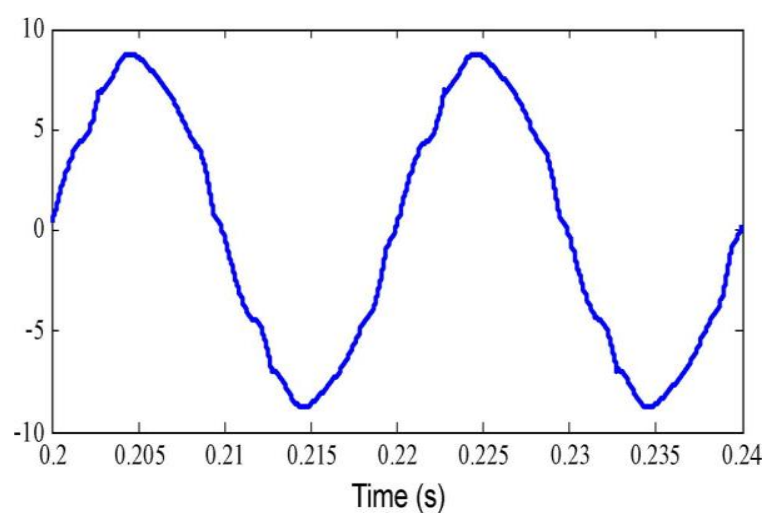

Fig 7 Source current when the passive filter is connected

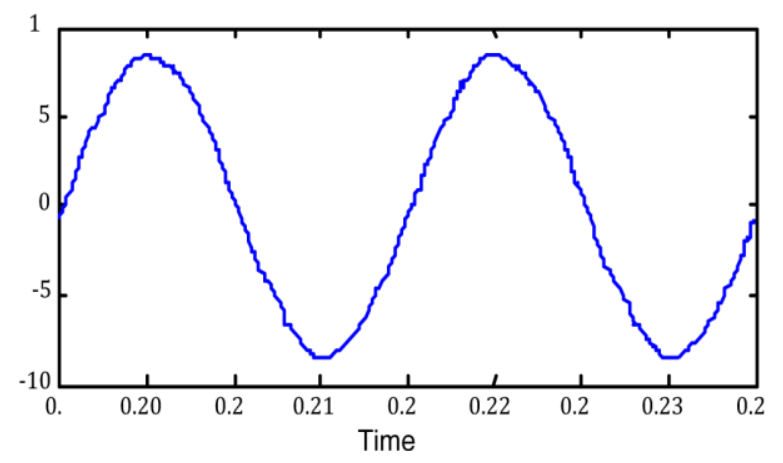

Fig 8 Source current when the active filter is connected

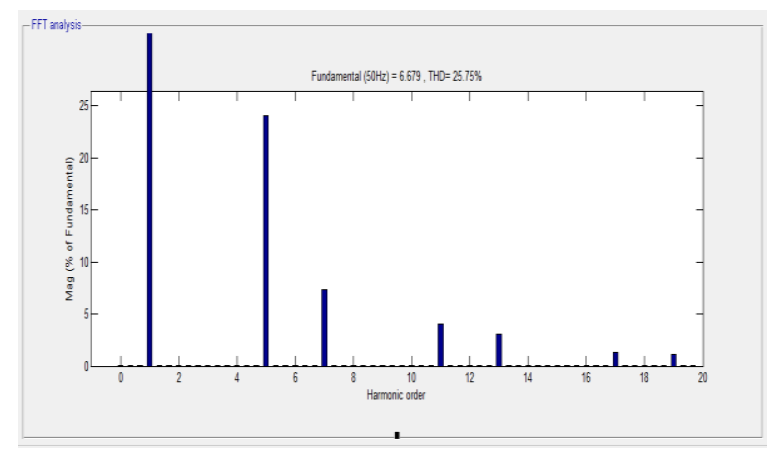

Fig 9: THD spectrum without filter

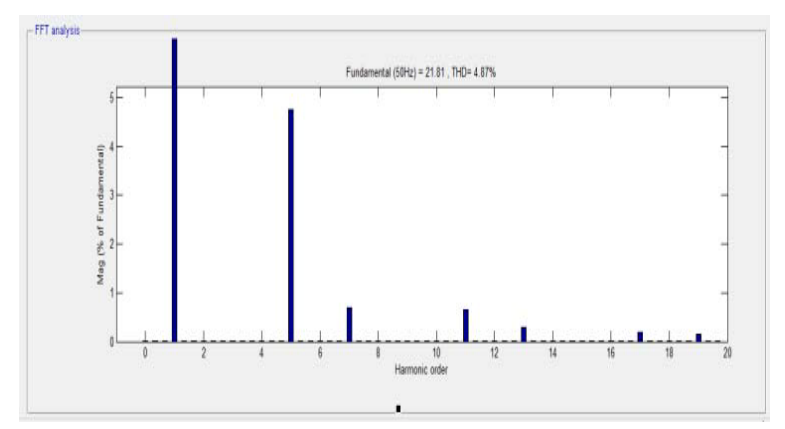

Fig 10: THD Spectrum with active power filter.

\section{CONCLUSIONS}

The SAPF explained in this paper compensate the line current harmonics generated due to the nonlinear loads in the system. HBCC technique used for the switching pulse generation was found to be effective and its validity is proved based on simulation results. Thus SAPF has been proved to be effective to keep the harmonic content in power lines within the permissible limit of IEEE standards.

\section{REFERENCES}

[1]. S. Sivanagaraju, and V.C.Veera Reddy(2011), "Design of Shunt Active Power Filter to eliminate the harmonic currents and to compensate the reactive power under distorted and or imbalanced source voltages in steady state", IJETTVol. 2 Issue 3

[2]. Y. P. Obulesh and Y. KusumaLatha(2011), "Control strategy for 3phase shunt active power filter with minimum current measurements", IJECE

[3]. A. Chandra and B. Singh (1999), "A Review on Active Filters for Power Quality Improvement", IEEE Trans. on IET, 46,5

[4]. Kamal Al-Haddad andNassar M (2000),"Modeling and Nonlinear Control of Shunt Active Power Filter in the Synchronous Reference Frame". IEEE Intl

[5]. Murat K. and EnginOzdhemier(2005), "An adaptive hysteresis band current controller for shunt active power filters", Electric Power Systems Research, 73, pp113-119

[6]. G. Bhuvaneswariand Charles. S(2010), "Comparison of Three Phase Shunt Active Power Filter Algorithms",IJCEE, 2,

[7]. G. Gurusamy and P.M. Balasubramaniam,." Evaluation and Implementation of Three Phase Shunt Active Power Filter for Power Quality Improvement”, IJCE.Vol. 5, No. 7 - 2012.

[8]. E. J. Acordi, A. Goedtel. and L. C. B. Nascimento, "A Study of Shunt Active Power Filters Applied to Three-Phase Four-Wire Systems", ICREPQ'12 - Spain, 28 - 30 March, 2012

[9]. H. Akagi, Y. Kanazawa, A. Nabae, Generalized Theory of the Instantaneous Reactive Power in Three-Phase Circuits, IPEC'83 - Int. Power Electronics Conf., Tokyo, Japan, 1983, pp. 1375-1386.

[10]. H. Akagi, Y. Kanazawa, A. Nabae, Instanataneous Reactive Power Compensator Comprising Switching Devices without Energy Storage Compenents", IEEE Trans. Industry Applic., vol. 20, May/June 1984.

[11]. E. H. Watanabe, R. M. Stephan, M. Aredes, New Concepts of Instantaneous Active and Reactive Powers in Electrical Systems with Generic Loads, IEEE Trans. Power Delivery, vol. 8, no. 2, April 1993, pp. 697-703.

[12]. M. Aredes, E. H. Watanabe, New Control Algorithms for Series and Shunt Three-Phase Four-Wire Active Power Filters, IEEE Trans. Power Delivery, vol 10, no. 3, July 1995, pp. 1649-1656.

[13]. J. Afonso, C. Couto and J. Martins, "Active Filters with Control Based on the p-q Theory", IEEE Industrial Electronics Society Newsletter, vol. 47, $\mathrm{n}^{\circ} 3$, Set. 2000, pp. 5-10. 
[14]. MATLAB: High-Performance Numeric Computation and Visualization Software - Reference Guide, The MathWorks Inc., April 1993.

[15]. SIMULINK: The Dynamic System Simulation SoftwareUser's Guide, The MathWorks Inc., April 1993.

[16]. J. Afonso, "Filtro Ativo Paralelo com Controlo Digital para a Melhoria da Qualidade de Energia Eléctrica", Ph.D. dissertation, University of Minho, 2000.

[17]. J. Afonso, M. Aredes, E. Watanabe e J. Martins, "Shunt Active Filter for Power Quality Improvement", Conference UIE 2000, Lisboa, 2000, pp. 683- 691. 